\title{
Electric Vehicle Charging Load Calculation Considering the Limitation of Charging length
}

\author{
Xiaoli Guo ${ }^{a}$, xin Xiao ${ }^{b}$ and Xinsong Zhang ${ }^{\mathrm{C}}$ \\ College of Electrical Engineering, Nantong University, No.9, Seyuan Road, Nantong, China \\ aguo.x|@ntu.edu.cn, b15162780701@163.com, prettypebble@163.com
}

\begin{abstract}
Keywords: Monte Carlo simulation; Charging load; Normal distribution; Charging time; State of charge
\end{abstract}

Abstract. Electric vehicle is becoming popular and will become an important load on electric systems as the oil resources exhaust. Studying the charging loads of electric vehicle is of great importance when analyzing the influence of grid-connected electric vehicles on the operation of electric system. The Monte Carlo simulation technology was utilized to simulate the charging load of a single electric vehicle, with considering different charging modes of electric private cars, taxies, buses and service cars. The total charging load was subsequently obtained based on the prediction of the inventory of electric vehicles. In the simulation, considerations have been given to the starting charging time, charging mode, initial state of charge (State of charge, SOC) and uncertainty of charging time on the one hand, on the other hand the considerations of the private car have been given to the limitation of the charging time in public places.

\section{Introduction}

Nowadays, with the blossom of new energy technologies, electric vehicle has now become a trend of the development of future auto industry. Electric vehicles, under current technical level, are charged mainly from power grid. Therefore, the great emergence of electric vehicles will have an profound effect on planning and operation of the power gird ${ }^{[1]}$. Obviously, studying the charging loads of electric vehicle is of great importance for power system ${ }^{[2,3]}$.

By now, many open literatures focused on charging load of electric vehicle, and a series of interesting results have been achieved ${ }^{[4-9]}$. By taking into account of daily driving modes and charging modes, Literature [4] conducted a study on features of the charging load under different economic control strategies, and applied those features to an analysis of a typical power distribution system. On the basis of investigations, several factors that affect charging power of electric vehicle are studied in Literature [5]. Furthermore, the effects of a large-scale electric vehicle charging on the original load curve had been calculated in this paper. In Literature [6], Monte Carlo simulation technology is utilized to study the effect when a large number of electric vehicles had been assessed to the power distribution network. Literatures [7,8] composed electric vehicle's historical load curves by using various one-day load distributions, obtaining the effect of electric vehicle's load curve on the total daily load curve. Based on the classification of the charging mode and charging time of electric vehicle, Literature [9] employed Monte Carlo simulation technology to calculate the charging load curve; however, the selections of the initial time and state of charge (SOC) state of charging are all subjective.

Another common limitation of Literatures [4-9] is that constraints on charging length are all ignored. On the contrast, electrical vehicles are assumed to be fully charged once they are connected to power grids for charging. In fact, when an electric vehicle is charged at a public site, its state of charge (SOC) cannot always reach the upper limit because of the limitation of the charging period. In present paper, the constraints of the electric vehicle's charging length are taken into consideration. In other words, when being charged at a public site, the charging period is set to be a fixed value. Furthermore, the charging loads of electric vehicles when charging at public places are compared under different charging probabilities. 


\section{Prediction of electric vehicle inventory}

Prediction of the number of electric vehicles is the basis for studying the charging loads. However, it is hard to make an accurate statistics of the inventory of electric vehicles, because the vehicles are widely distributed as well as the uncertainty in purchase. Generally, it is feasible to predict the inventory of electric vehicles by calculating the increment ${ }^{[10]}$. Common prediction methods include: regression analysis, elastic coefficient, situated analogy, exponential smoothing, inventory per 1000 people, artificial neural network, chaotic time series and combinatorial forecast, etc ${ }^{[11-13]}$.

According to statistics, by the end of 2012, the total number of electric vehicles in Beijing was 34130 , of which, private cars occupied the largest proportion of $84 \%$, followed by service cars, reaching $12 \%$, and the rest made up by buses and taxies. On the data ground, this paper employs the Bass model to predict the inventory of electric vehicles in Beijing during 2013-2020, and its mathematical model is expressed as:

$$
f(t+1)=p[1-F(t)]+q F(t)[1-F(t)] .
$$

where, $f(t+1)$ is a proportion of the number of the new consumers increased during $t+1$ to the number of the potential consumers during $t+1 ; F(t)$ is a proportion of the number of the consumers accumulated during $t$ to the number of the potential consumers during $t ; p$ is a external influence coefficient (innovation coefficient), $q$ is a internal influence coefficient (imitation coefficient), which reflects the number of the consumers who are affected by the network effect as well as by others' purchase decisions. Tables 1 and 2 list the values of $p$ and $q$ in our study ${ }^{[14]}$ :

Tab.1 Values of parameter $p$ during 2012-2020

\begin{tabular}{cccccc}
\hline Year & 2012 & 2013 & 2014 & 2015 & 2016 \\
\hline High-price oil & 0.0200 & 0.0210 & 0.0219 & 0.0228 & 0.0236 \\
Low-price oil & 0.0100 & 0.0105 & 0.0110 & 0.0114 & 0.0118 \\
Year & 2017 & 2018 & 2019 & 2020 & \\
High-price oil & 0.0243 & 0.0249 & 0.0254 & 0.0258 & \\
Low-price oil & 0.0122 & 0.0125 & 0.0127 & 0.0129 & \\
\hline
\end{tabular}

Tab.2 Values of parameter $q$ during 2012-2020

\begin{tabular}{cccccc}
\hline Year & 2012 & 2013 & 2014 & 2015 & 2016 \\
\hline High-price oil & 0.4000 & 0.4200 & 0.4431 & 0.4697 & 0.5002 \\
Low-price oil & 0.3000 & 0.315 & 0.3323 & 0.3523 & 0.3752 \\
Year & 2017 & 2018 & 2019 & 2020 & \\
High-price oil & 0.5352 & 0.5754 & 0.6214 & 0.6742 & \\
Low-price oil & 0.4014 & 0.4315 & 0.4661 & 0.5057 & \\
\hline
\end{tabular}

\section{Analysis of random factors}

Electric bus

Electric buses are running on fixed routes everyday. A bus generally starts at 6:00 a.m. and ends at 10:00 p.m. and runs $200 \mathrm{~km}$ everyday. There are two peak periods, i.e., 7:00-9:00 a.m. and 17:00-19:00 p.m. It is obvious that charging time of electric buses should avoid these two peak periods.

An electric bus is charged twice a day. The first time is scheduled in the morning and the second time is scheduled in the evening. In order to ensure normal operation the charging models of this two 
charging are respectively to be quick charging and conventional charging. The daytime charging period is 10:00-16:30 and the nighttime charging period is 23:00-5:00. The initial SOC is a random variable, following the normal distribution of $N\left(0.5,0.1^{2}\right)$. The charging length of the electric bus is ignored in this paper, i.e., it will be fully charged once the charging is started ${ }^{[9]}$. For electric buses, the starting charging time follows uniform distribution during the charging period.

Electric taxi

In general, a taxi runs about $500 \mathrm{~km}$ everyday. The double-shift is typical pattern of taxi operation, i.e. a taxi is generally handed over at 9:00 a.m. and 21:00 p.m., respectively ${ }^{[15]}$. For operation convenience, the quick charging mode is more usually used to charge the taxi before it being handed over. For electric taxies, the starting charging time and the initial SOC are all random variables. This paper assumes that the two starting times follow the normal distributions of $N\left(8,0.5^{2}\right)$ and $N\left(20,0.5^{2}\right)$, respectively, and the initial SOC obeys the normal distribution of $N\left(0.3,0.1^{2}\right)$. Electric service car

Basically, electric service cars are running during daytime, and are charged using the conventional mode at parking lot. The starting charging time and the initial SOC are random variables, which follow the uniform distribution of $U(18,24)$ and the normal distribution of $\mathrm{N}\left(0.4,0.1^{2}\right)$, respectively. Electric private car

Owners of electric private cars drive their electric private cars for commuting between offices and home, shopping and entertainments. A private car runs about $40 \mathrm{~km}$ a day[16], as a result, one charge per day can meet its driving demand.

During workdays, electric private cars are mainly used as communication media to carry people to offices, and the peak periods are 7:00-9:00 and 17:00-19:00, respectively. For car owners, they can use the conventional charging mode to charge their cars during the working hours at the parking lots near their working sites, or, at living quarters after they go back home. Obviously, the starting charging time and the initial SOC are random variables no matter where the car is charged. This paper assumes that the starting charging times at the parking lots and living quarters follow the normal distributions of $\mathrm{N}(9,0.52)$ and $\mathrm{N}(19,0.52)$, respectively, and the initial SOC follows the normal distribution of $\mathrm{N}(0.6,0.12)$.

During holidays, car owners can charge their cars either at public sites (supermarkets, malls, etc.) or living quarters. According to data statistics on people's habits, it is reasonable to assume that the period when private cars are charged at public sites is 12:00-22:00, out of which the cars are charged at living quarters. However, the time to park at a public site is limited. According survey data, the average length for private cars to park at public sites is about $80 \mathrm{~min}$.

So we will have a certain limit on the electric vehicle charging in public places. The time limitation is 80 minutes.

As can be seen from the survey result, there are two peak charging periods: 20:00p.m.-5:00a.m. and 0:00a.m.-7:00a.m. During holidays, therefore, the starting charging time of private cars charged in living quarters follows the uniform distributions of $U(20,29)$ and $U(0,7)$, respectively. Quick charge will greatly reduce the service life of batteries, so conventional charging model is often chosen by owners of electric private cars if there are no special requirements. For public sites, the starting charging time follows the uniform distribution of $\mathrm{U}(12,22)$ and the initial SOC follows the normal distribution of $\mathrm{N}\left(0.6,0.1^{2}\right)$. 
Tab.3 The charging parameters of the four types of electric vehicle

\begin{tabular}{|c|c|c|c|c|c|c|}
\hline $\begin{array}{l}\text { Vehicle } \\
\text { Type }\end{array}$ & $\begin{array}{l}\text { Charging } \\
\text { Frequency } \\
\text { per Day }\end{array}$ & Period & $\begin{array}{c}\text { Distribution } \\
\text { of Starting } \\
\text { Charging } \\
\text { Time }\end{array}$ & $\begin{array}{l}\text { Distribution } \\
\text { of Initial } \\
\text { SOC }\end{array}$ & $\begin{array}{l}\text { Limitation } \\
\text { of Charging } \\
\text { Time }\end{array}$ & $\begin{array}{c}\text { Charging } \\
\text { Mode }\end{array}$ \\
\hline \multirow{2}{*}{ Bus } & \multirow{2}{*}{2} & $10: 00-16: 30$ & $\mathrm{U}(10,16.5)$ & $\mathrm{N}(0.5,0.01)$ & No & Quick \\
\hline & & 23:00-5:00 & $\mathrm{U}(23,29)$ & $\mathrm{N}(0.5,0.01)$ & No & Conventional \\
\hline \multirow{2}{*}{ Taxi } & \multirow{2}{*}{2} & & $\mathrm{~N}(8,0.25)$ & $\mathrm{N}(0.3,0.01)$ & No & Quick \\
\hline & & & $\mathrm{N}(20,0.25)$ & $\mathrm{N}(0.3,0.01)$ & No & Quick \\
\hline $\begin{array}{l}\text { Service } \\
\text { car }\end{array}$ & 1 & 18:00-7:00 & $\mathrm{U}(18,31)$ & $\mathrm{N}(0.4,0.01)$ & No & Conventional \\
\hline Private & \multirow[b]{2}{*}{1} & 7:30-17:00 & $\mathrm{N}(9,0.25)$ & $\mathrm{N}(0.6,0.01)$ & No & Conventional \\
\hline $\begin{array}{l}\text { car } \\
\text { (working } \\
\text { days) }\end{array}$ & & 19:00-7:00 & $\mathrm{N}(19,1.25)$ & $\mathrm{N}(0.6,0.01)$ & No & Conventional \\
\hline Private & \multirow{3}{*}{1} & $20: 00-5: 00$ & U $(20,29)$ & $\mathrm{N}(0.6,0.01)$ & No & Conventional \\
\hline & & 0:00-7:00 & $\mathrm{U}(0,7)$ & $\mathrm{N}(0.6,0.01)$ & No & Conventional \\
\hline (holidays) & & $12: 00-22: 00$ & $\mathrm{U}(12,22)$ & $\mathrm{N}(0.6,0.01)$ & $80 \mathrm{~min}$ & Conventional \\
\hline
\end{tabular}

\section{Calculation of charging load of electric vehicle}

Calculation model

The charging load of a single electric vehicle should be calculated firstly, then, the total charging load of all electric vehicles can be subsequently achieved by summing up these single charging loads. In this paper, the Monte Carlo simulation technology is utilized to simulate charging behaviors of electric vehicles when considering random factors listed above. The charging load is calculated with the unit of day, the time resolution is accurate to min, a total of 1440min.Assume that $Q_{\mathrm{i}}$ is the charging load of all electric vehicles at the moment $i$, then the total charging load is:

$$
Q_{i}=\sum_{\mathrm{n}=1}^{N} P_{n, i} i=1,2, \ldots, 1440
$$

where, $N$ is the total number of the vehicles, $P_{n, i}$ is the charging power of the $\mathrm{n}^{\text {th }}$ electric vehicle at the moment $i$.

Calculation method

The basic idea of Monte Carlo method is to establish a probability model or a random process model, By collecting a large number of random samples to achieve the simulation process and get an estimate of its statistical law, and use the statistical probability of a parameter in a large number of random samples under the parameter as a measure of an estimate. A precondition of Monte Carlo method, however, is that the random number must be generated via computer and any probability distribution can be randomly sampled ${ }^{[17]}$. There are three major steps when the Monte Carlo method is used to solve a problem, as shown in fig. 1 


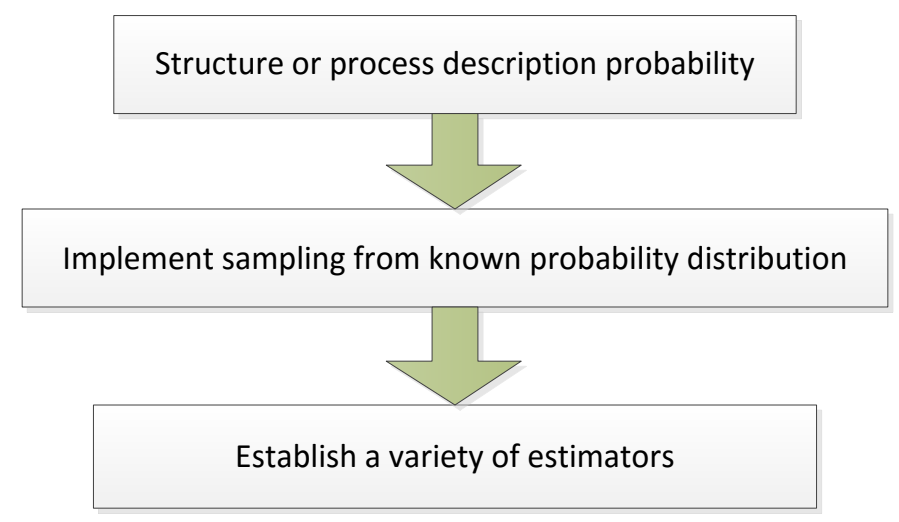

Fig.1 The main problem solve steps of monte carlo

Here gives following assumptions:

(1) The battery capacities of the bus, the taxi, the car and the private car are respectively assumed to be $105 \mathrm{kwh}, 72 \mathrm{kwh}, 35 \mathrm{kwh}$ and $35 \mathrm{kwh}$.

(2) An electric vehicle is immediately charged after returning from the last trip.

(3) All vehicles are charged at the rated current of $1.25 \mathrm{C}$ when the quick charge mode is selected, or at the rated current of $0.2 \mathrm{C}$ in the model of conventional charging. That is to say, the quick charge mode requires $0.8 \mathrm{~h}$ to fully charge a battery from zero state, while the conventional one only requires $5 \mathrm{~h}$.

(4) If the constraint on charging length is ignored, the battery will be fully charged, on the contrast, the battery will be charged till the time limit is reached. when the constraint on charging length is considered.

(5) The starting charging time, charging power, initial SOC are random variables and are independent from each other.

It is assumed that system operators exert no controls on the charging behavior of electric vehicles, namely, an electric is immediately charged at the moment when it is connected to the power grids. The first step before charging is to make sure that whether there is a constraint on charging length or not. If you choose the charging time length has been limited, firstly, the starting SOC is extracted from a given time period, and then calculate the required charging time length. Based on the time limitation, the length of the charging time is then calculated. The starting charging time is set at a given length as well, based on which, the charging load can be calculated. If there is no time limitation, the initial SOC in simulation is set at the first, and the required charging time is calculated. Then, figure out the starting charging time to calculate the charging load. For easy viewing, we have simplified this calculation process into a flow chart, as shown in fig. 2, where the Monte Carlo simulation is used to calculate the charging load. In this studying system, the input information includes: vehicle inventory, probability distributions of the initial SOC under different charging modes, probability distributions and time limitations of the starting charging time. 


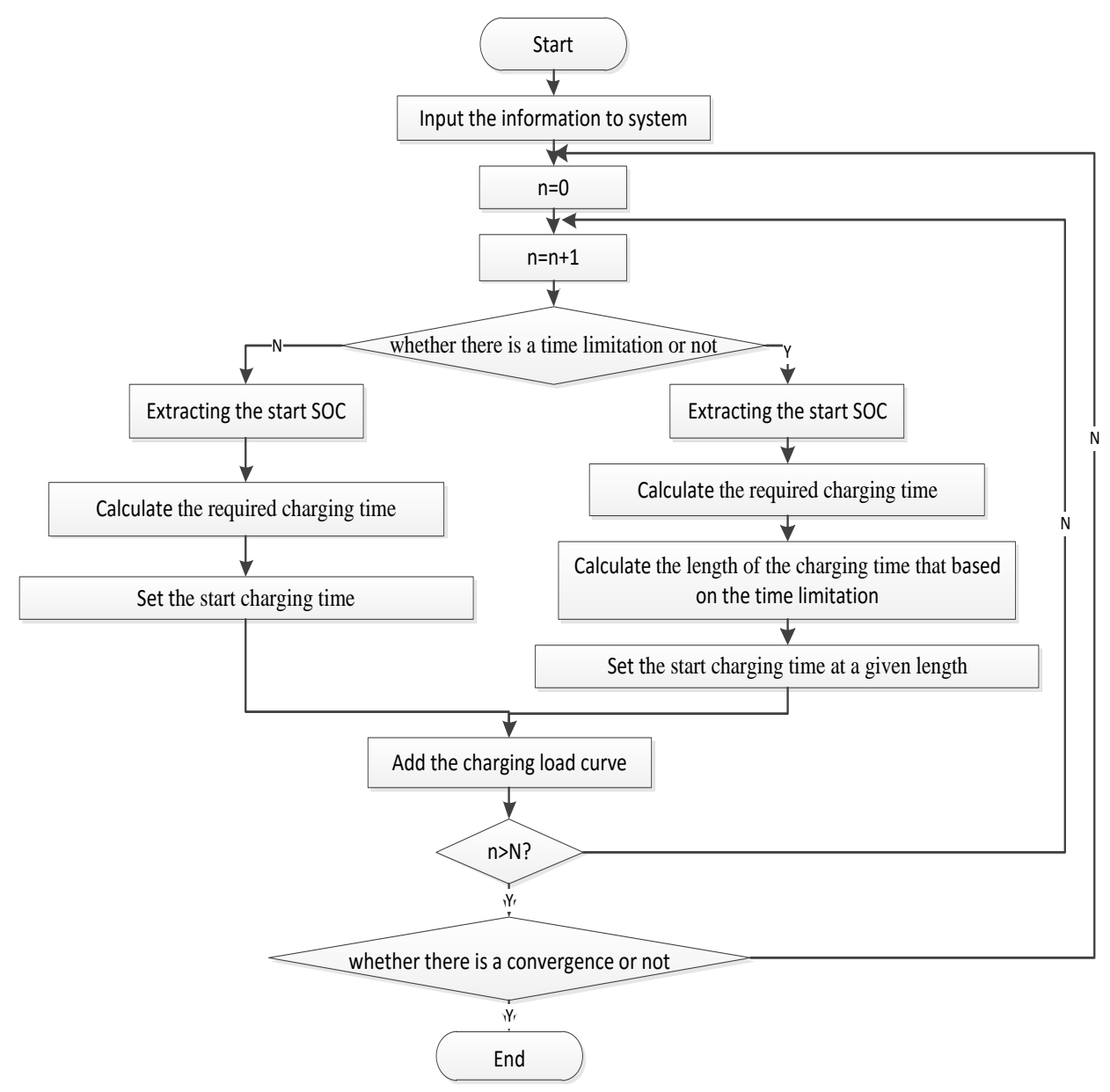

Fig.2 Flow chart of proposed algorithm based on Monte Carlo simulation

\section{Example analysis}

Prediction results of electric vehicle inventory

In the future, electric vehicles on global market will experience different development prospects because of the uncertainty in driving factors of macro development, which requires a comprehensive consideration of many factors to make scale prediction. According to Kearney's analysis ${ }^{[18]}$,oil price has the greatest influence on future numbers of electric vehicles and is hard to be predicted. Therefore, two extreme oil prices scenarios are considered when predicting the inventory of electric vehicles, named respectively as high-price oil and low-price oil.

A survey report shows that, the total number of electric vehicles in Beijing in 2012 is 34130, According to the calculation of proportion, 28669 are private cars, 4095 are service cars, 956 are taxies and 410 are buses. According to the prediction method mentioned in section 1, the prediction results of electric vehicle inventory in Beijing in the next few years can be obtained, as shown in tables 4-7:

Tab.4 Electric bus inventory of every year from 2012 to 2020

\begin{tabular}{clllllllll}
\hline Year & 2012 & 2013 & 2014 & 2015 & 2016 & 2017 & 2018 & 2019 & 2020 \\
\hline High-price oil & 410 & 679 & 968 & 1287 & 1645 & 2054 & 2527 & 3071 & 3711 \\
Low-price oil & 410 & 595 & 766 & 944 & 1119 & 1311 & 1524 & 1765 & 2036 \\
\hline
\end{tabular}


Tab.5 Electric taxi inventory of every year from 2012 to 2020

\begin{tabular}{cccccccccc}
\hline Year & 2012 & 2013 & 2014 & 2015 & 2016 & 2017 & 2018 & 2019 & 2020 \\
\hline High-price oil & 956 & 1585 & 2259 & 3003 & 3839 & 4793 & 5896 & 7167 & 8658 \\
Low-price oil & 956 & 1388 & 1788 & 2203 & 2612 & 3058 & 3556 & 4117 & 4750 \\
\hline
\end{tabular}

Tab.6 Electric official vehicle inventory of every year from 2012 to 2020

\begin{tabular}{clllllllll}
\hline Year & 2012 & 2013 & 2014 & 2015 & 2016 & 2017 & 2018 & 2019 & 2020 \\
\hline High-price oil & 4095 & 6794 & 9680 & 12871 & 16452 & 20541 & 25167 & 30714 & 37108 \\
Low-price oil & 4095 & 5948 & 7663 & 9443 & 11193 & 13106 & 15242 & 17646 & 20359 \\
\hline
\end{tabular}

Tab.7 Electric private car inventory of every year from 2012 to 2020

\begin{tabular}{llllllllll}
\hline Year & 2012 & 2013 & 2014 & 2015 & 2016 & 2017 & 2018 & 2019 & 2020 \\
\hline High-price oil & 28669 & 47561 & 67761 & 90094 & 115162 & 143790 & 176867 & 214998 & 259755 \\
Low-price oil & 28669 & 41638 & 53638 & 66104 & 78348 & 91745 & 106691 & 123519 & 142514 \\
\hline
\end{tabular}

The electric vehicle inventories in Beijing in the next few years, as listed in the above tables, are calculated by using the Bass model. It can be seen that electric vehicles have a good development prospect in years to come, especially private electric cars which are the main force in future development. In this study, the charging powers of the four types of the electric vehicle are calculated, respectively, with taking into consideration of the high-price oil and low-price oil in 2015. The high-price oil can better reflect the actual situation, so, for the four types of the electric vehicles, the charging loads in 2015 and 2020 are calculated and compared under the situation of the high-price oil. Calculation results and analysis of charging load

With the prediction results of the electric vehicle inventory, the $48 \mathrm{~h}$ charging load curves of the electric vehicles in Beijing in 2015 can be obtained, as shown in fig. 3: 


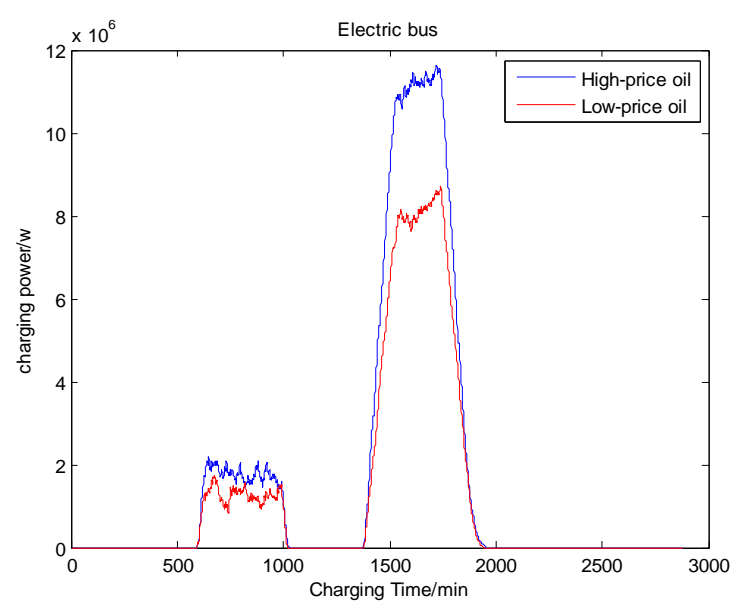

(a)

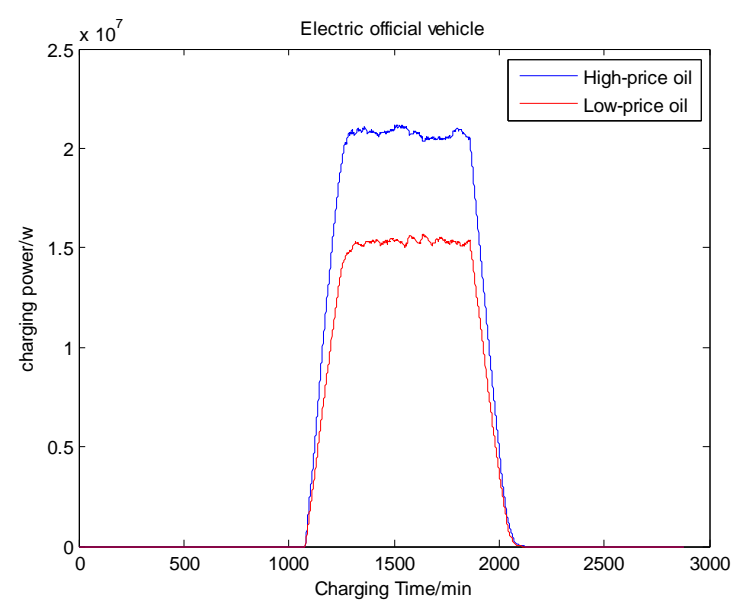

(c)

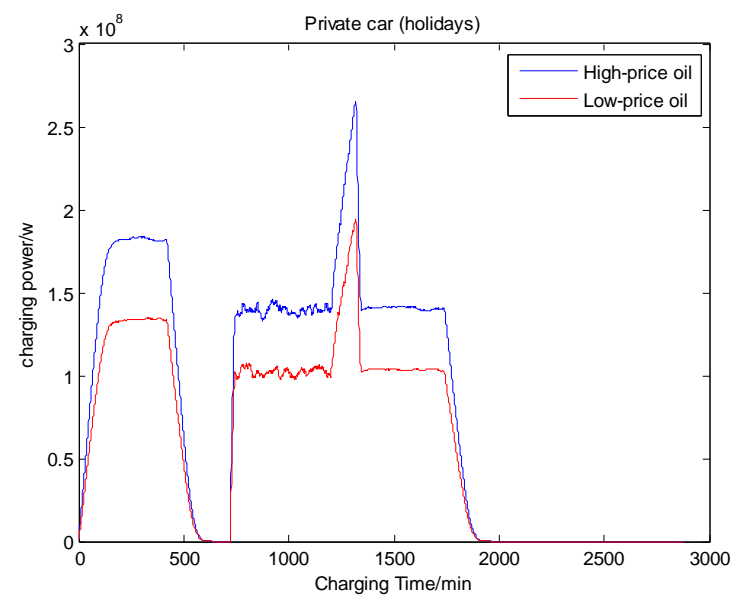

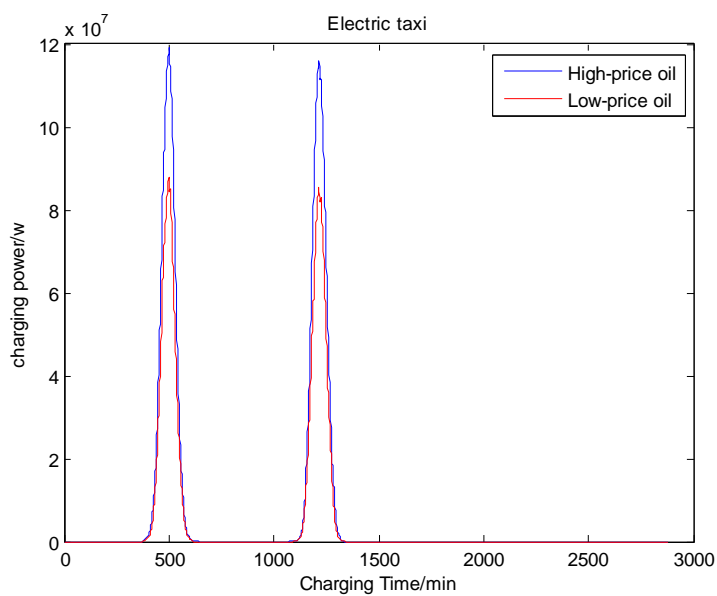

(b)

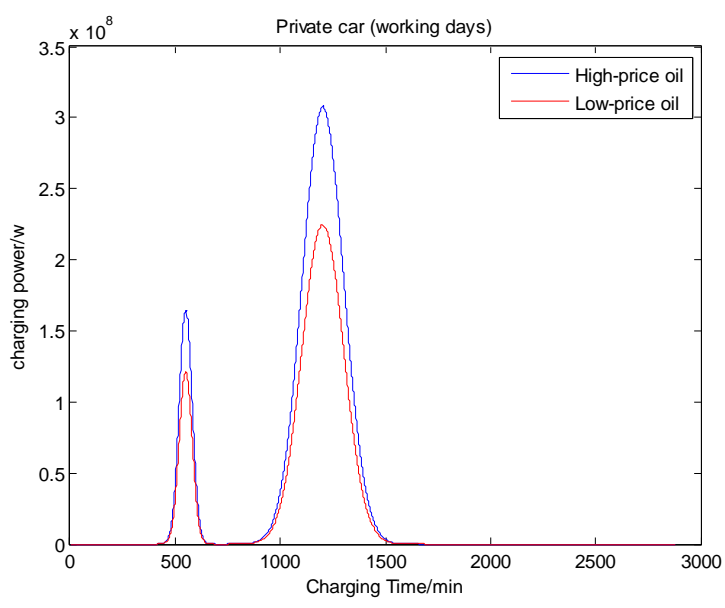

(d)

(e)

Fig3. Prediction of charging curves in Beijing in 2015

As can be seen from fig. 3(a)-(e), if limitations on charging of electric vehicle are not conducted, there is always a huge valley-to-peak difference in charging loads of four type of electric vehicles. The higher the oil price is, the larger the number of electric vehicles will be. So, the charging loads under the high-price mode are always higher than those under the low-price mode. It is easy to see from fig. 3 that private cars have the highest charging load, which, therefore, causes the strongest impact on the power gird. Private cars are likely to become the main force of the development of electric vehicles. 
The comparative analysis shows a grim situation of charging load under the high-price oil conditions. In order to make clear of the development trend of electric vehicles, we have calculated the charging loads of the electric vehicles in Beijing in 2012 as well as in 2020, respectively. The electric vehicle inventories are predicted under the high-price oil conditions. The charging load curves are shown in fig. 4

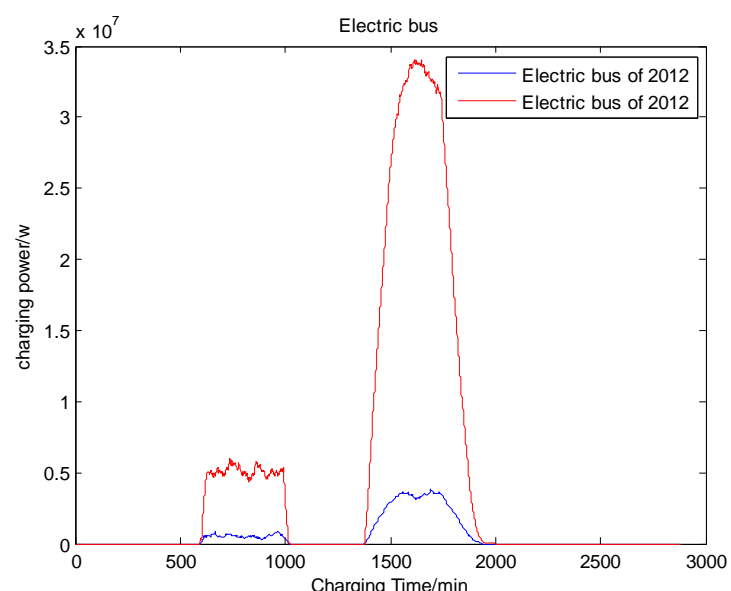

(a)

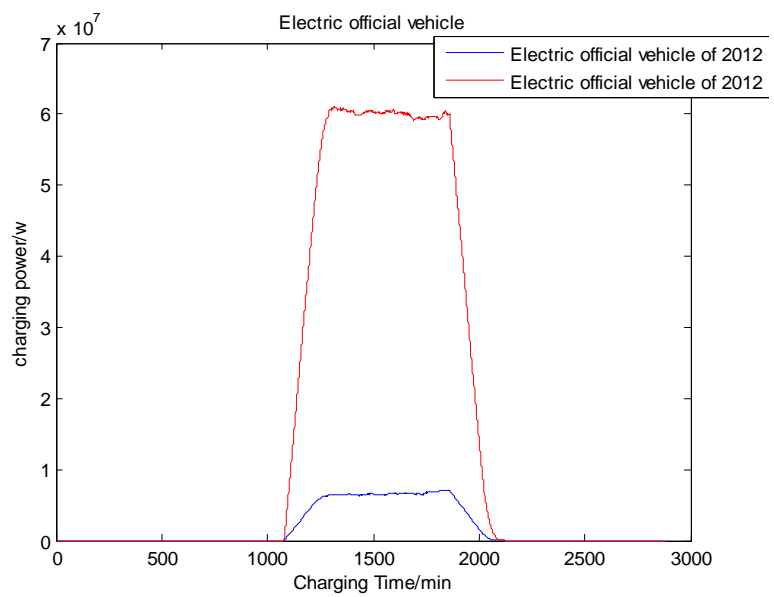

(c)

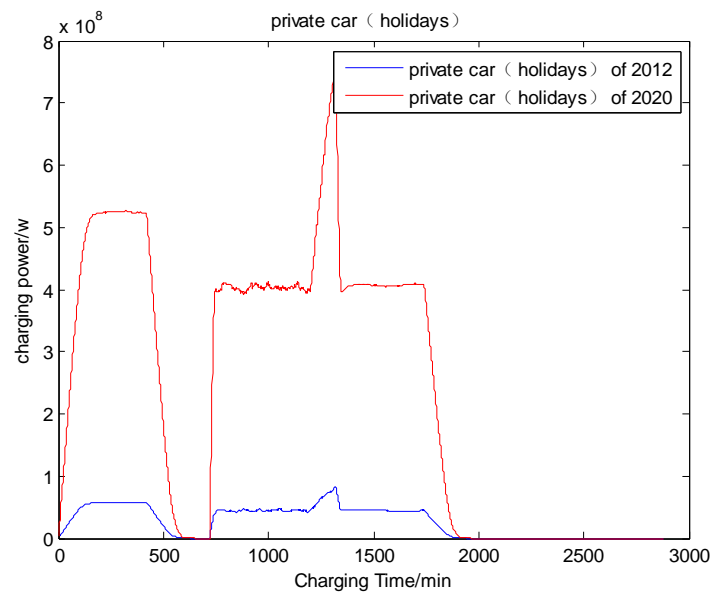

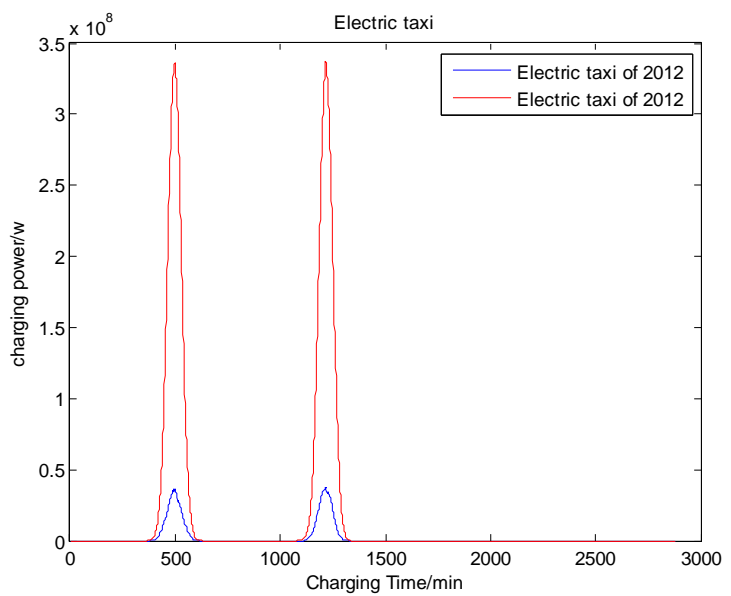

(b)

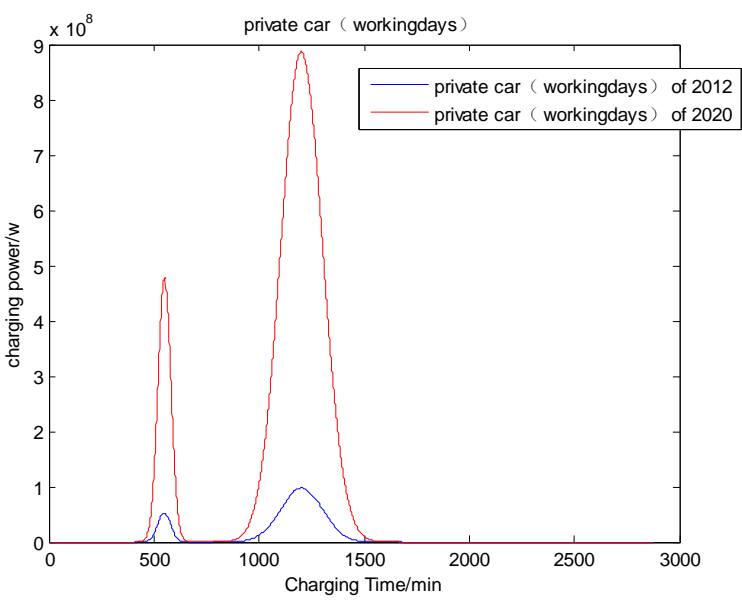

(d)

(e)

Fig4. Prediction of charging curves in Beijing in 2012,2020 
As can be seen from fig. 4(a)-(e), during the short period from 2012 to 2020, all types of electric vehicle will be enjoying a good development, and the peak charging hours converge to 8:30-10:00 and 20:00-23:00. Therefore, effective means shall be taken to chip the peak off and fill the valley up, so as to minimize the impact of electric vehicles on the power grid and improve the reliability of power supply as well. Private cars are the main force of the development of electric vehicles in future. It is random for private cars to go out on holidays, and it is easier to control when to charge private cars. Therefore, charging loads of private electric vehicles are calculated, with different probabilities on holidays, as shown in fig. 5.

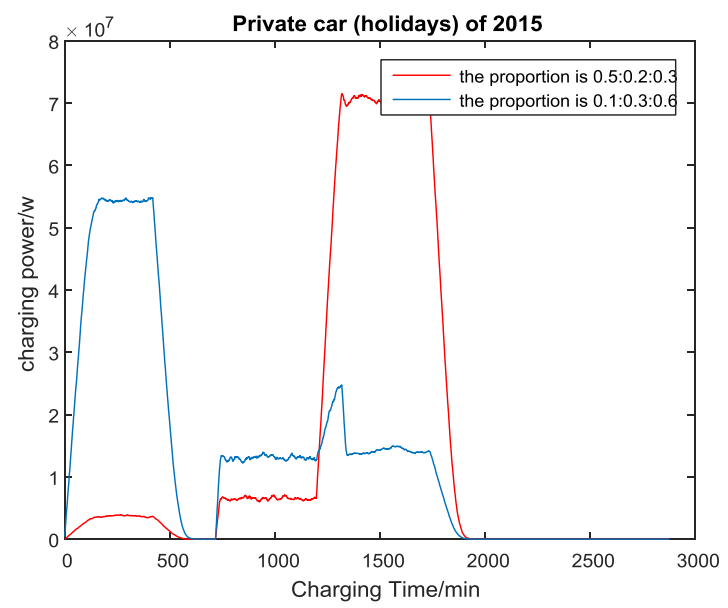

Fig5. The electric vehicle charging curves under different charging probability in Beijing in 2015

Fig. 5 depicts the charging load curves with different proportions of private cars that are charged in living quarters during 20:00- 5:00 and 0:00-7:00 as well as charged at public sites during 12:00-22:00. The red curve corresponds to the proportion of $0.5: 0.2: 0.3$, while the blue curve corresponds to the proportion of 0.1:0.3:0.6. It can be seen from fig. 5 that the proportion has a great influence on charging load. The simulation result of the red curve can better reflect people's charging habits. There is a peak period of electricity utilization after 20:00, and most people charge their cars during this period, which impose a great threat upon the reliability of power supply. Hence, if the charging behavior can be controlled by using effective means, the impact of private cars on power gird can be remarkably reduced. Future studies shall be directed to the dispatching of charging energy. This can efficiently increase the energy utilization rate, and, to some degree, avoid the impact on the power grid due to disordered charges.

\section{Conclusion}

In this paper, the electric vehicle charging load of Beijing city is been calculated based on the forecast results of the electric vehicle, The calculation method is Monte Carlo simulation method. But some data may have some errors, and all of the above results are under the situation that all the cars are charged, that has a certain subjective and limitations, but the results can be used as a reference.

As the electric car is not really popular in the country, therefore, the relevant data in the text are aimed at Beijing, but the researching method can be used in other areas, it is layed the foundation for researching the electric vehicle charging in other areas.

\section{References}

[1] Zhang Wenliang, Wu Bin, Li Wufeng; Discussion on Development Trend of Battery Electric Vehicles in China and Its Energy Supply Mode [J]. Power System Technology, 2009,33(4):1-5. 
[2] Xue Zhongbing, Peng Cheng; Research on the Coordinated Operation of New Energy Power Generation and EV Charging Storage Station [J]; Jiangsu Electrical Engineering, 2014,35(5): 36-38.

[3] Wang Xifan, Shao Chengcheng, Wang Xiuli, Du Chao; Survey of Electric Vehicle Charging Load and Dispatch Control Strategies [J]; Proceedings of the CSEE, 2013,33(1):1-10.

[4] Xu Lizhong, Yang Guangya, Xu Zhao, F.MARRA, C.TRAHOLT; Impacts of Electric Vehicle Charging on Distribution Networks in Denmark [J]; Automation of Electric Power Systems, 2011,35(14):18-23.

[5] Tian Liting, Shi Shuanglong, Jia Zhuo; A Statistical Model for Charging Power Demand of Electric Vehicles [J]; Power System Technology, 2010,34(11):126-130.

[6] Yu Haojun, Liang Xi, Xu Wenchao, Niu Tao, Han Zhikun; Charging Load Calculation of Electric Vehicles Under Normal Charging Mode and Battery Exchange Mode [J]; Jiangsu Electrical Engineering, 2015,34(2):58-61.

[7] Putrus G, Suwanapingkarl A, Johnston P. Impact of electric vehicles on power distribution networks[C]//IEEE Vehicle Power and Propulsion Conference, Dearborn, USA , 2009:827-832.

[8]Wynne J. Impact of plug-in hybrid electric vehicles on California's electricity grid[D]. North California: Nicholas School of the Environment of Duke University, 2009.

[9] Luo Zhuowei, Hu Zhechun, Song Yonghua; Study on Plug in Electric Vehicles Charging Load Calculation [J]; Automation of Electric Power Systems, 2011,35(14):36-42.

[10] Wang Ruimiao, Chen Tao, Liu Yongxiang; Electric Vehicle Holdings Prediction Using Elasticity and Thousand Holdings Methods [J]; Agricultural Equipment \& Vehicle Engineering, 2011(6),40-48.

[11] Sandels, C., Franke, U., Ingvar, N., et al. (2010) Vehicle to grid-Monte Carlo simulations for optimal aggregator strategies. Proceedings of International Conference on Power System Technology, Hangzhou, 24-28 October 2010, 1-8.

[12] Chen Diyi, Liu Ye, Ma Xiaoyi (2012); Parameter Joint Estimation of Phase Space Reconstruction in Chaotic Time Series Based on Radial Basis Function Neural Networks; Acta Physica Sinica, 61, 100501.1-100501.9.

[13] Chen, D.Y. and Han, W.T. (2013) Prediction of multivariate chaotic time series via radial basis function neural network. Complexity, 18, 55-66.

[14] Zeng Ming, Zeng Fanxiao, Zhu Xiaoli, Xue Song; Forecast of Electric Vehicles in China Based on Bass Model [J]; Electric Power, 2013,46(1): 36-39.

[15] Bie Zhaohong, Wang Xifan; The Application of Monte Carlo Method to Reliability Evaluation of Power Systems [J]; Automation of Electric Power Systems, 1997,21(6):68-75.

[16] Yuan Zhengping, Zhou Wei, Wang Wenbin; Charging Load Forecasting Method for Electric Vehicles [J]; East China Electric Power, 2013, 41(12): 2567-2572.

[17]Bi Jun, Zhang Jiawei, Zhang Dong, Cheng Yong; A Correlation Analysis and Modeling for Battery SOC and Driving Mileage of Electric Vehicle [J]; Journal of Transportation Systems Engineering and Information Technology, 2015,15(1):49-54.

[18]BECKER T A, TENDERICH B. Electric vehicles in the United States: a new model with forecasts to 2030 [R].Center for Entrepreneurship \&Technology (CET),2009,2009.1.v.2.0. 
